\title{
A Remote Lab Experiments Improved Model
}

\author{
doi:10.3991/ijoe.v7i1.1460 \\ C. Riman ${ }^{1}$, A. El Hajj ${ }^{2}$ and I. Mougharbel ${ }^{3}$ \\ ${ }^{1}$ Fahad Bin Sultan University, Tabuk, KSA, ${ }^{2}$ American University of Beirut, Beirut, Lebanon \\ ${ }^{3}$ Lebanese University, Beirut, Lebanon
}

\begin{abstract}
Remote Laboratory Experimentation (RLE) is a technique used in modern engineering laboratories to help academic researchers and students perform laboratory experiments remotely through the internet. Due to the lack of well specified requirements for RLE, many RLE implementation models exist with different characteristics, using different technologies, and without a consistent set of services. In this work, the services provided by some recent RLE implementations models are identified, these services are analyzed, and specifications of a general improved model are concluded.
\end{abstract}

Index Terms-Remote Laboratory Experiment, Distance Learning, LabVIEW, Education.

\section{INTRODUCTION}

Remote Laboratory Experimentation (RLE) is a technique used in modern engineering laboratories to help academic researchers and students perform laboratory experiments remotely through the Internet [1-2]. From the client side, a computer is connected to the internet with a Web browser from which the real experiment is to be conducted. On the server side, there are two important components: A lab server and a Web server. The lab server consists of a computer connected to the experiment's hardware and possibly to a webcam. The Web server, which is connected to the lab server, is responsible of managing the access by clients to the experimental setup. RLE offers the following advantages:

- Reduces travel time and cost (e.g. for having to be physically in the lab where the experiment is performed)

- Supports ubiquitous computing (it is not confined to space and time)

- Allows accessibility for the disabled.

- Promotes student self-learning when used for education.

- Allows for time sharing of experimental hardware.

- Provides for resource sharing by organizations for unique or expensive equipment.

- Provides scalability in terms of user sessions and experiment size.

- Permits for storing experiment data and for playing back the results to perform inspection analysis.

- Allows for demonstrating of real experiments through seminars or presentations.

\section{RLE SERVICES}

In order to identify the services that RLEs must provide, eight existing models[3-10] were studied and com- pared in [1]. The technology used in their implementation is described, their characteristics are evaluated, and the services they provide are identified and summarized in table I. It was found that these models provide services such as concurrency, collaboration, authentication, video streaming, data archiving, scheduling, and administration. Each of these services has varying characteristics in the different models. This diversity is due to the lack of studies on the requirement specifications and standardization of RLE models and systems.

TABLE I.

SERVICES PROVIDED BY DIFFERENT MODELS

\begin{tabular}{|c|c|c|c|c|c|c|c|c|}
\hline Model & 1 & 2 & 3 & 4 & 5 & 6 & 7 & 8 \\
\hline Authentication & $X$ & $\mathrm{X}$ & $X$ & $\mathrm{X}$ & & & $\mathrm{X}$ & $\mathbf{X}$ \\
\hline Scheduling & $\mathrm{X}$ & $\mathrm{X}$ & $\mathrm{X}$ & $\mathrm{X}$ & & & & $\mathrm{X}$ \\
\hline Video Streaming & $\mathrm{X}$ & $X$ & $\mathrm{X}$ & $\mathrm{X}$ & & & & $\mathrm{X}$ \\
\hline Data Archiving & & $\mathrm{X}$ & & & & & $\mathrm{X}$ & \\
\hline Collaboration & $\mathrm{X}$ & & $\mathrm{X}$ & & & & & $X$ \\
\hline Concurrency & $\begin{array}{l}\text { Multi } \\
\text { Read, } \\
\text { One } \\
\text { Write }\end{array}$ & $\begin{array}{c}\text { Multi } \\
\text { Read, } \\
\text { One } \\
\text { Write }\end{array}$ & $\begin{array}{c}\text { Multi } \\
\text { Read, } \\
\text { One } \\
\text { Write }\end{array}$ & & & & & \\
\hline $\begin{array}{c}\text { System Administra- } \\
\text { tion }\end{array}$ & $\mathrm{X}$ & $X$ & $X$ & & $\mathrm{X}$ & & $\mathrm{X}$ & \\
\hline $\begin{array}{l}\text { Web system Admini- } \\
\text { stration }\end{array}$ & & $\mathrm{X}$ & $\mathrm{X}$ & & & & $\mathrm{X}$ & \\
\hline
\end{tabular}

Collaboration, as it relates to this study, is related to a group of many students at different locations who are conducting the same experiment. This can be facilitated by existing groupware and collaborative technologies such as Netmeeting and Lotus Notes, in addition to customized tools to share the access of an instrument or tool. Concurrency is to allow different students to simultaneously access an experiment in read and/or write mode. Video streaming is used to add the feeling of physical presence at the experiment's site through the employment of a video camera. Data archiving is used to make results from experiments persistent and available for later usage by students and instructors. Scheduling is implemented to facilitate access to the lab experiments without conflicts and congestion. Finally, authentication is used in order to restrict access to the lab experiments to authorized users only. These services are represented by modules that interact. This interaction is shown in figure 1 which represents an improved model containing all the positive aspects of the discussed models.

This model is based on a layers architecture layer 0 to layer 2. Layer 0 includes the actual experimentation. Layer 1 includes the basic modules (database, data archiving, video server, collaboration, authentication and sched- 


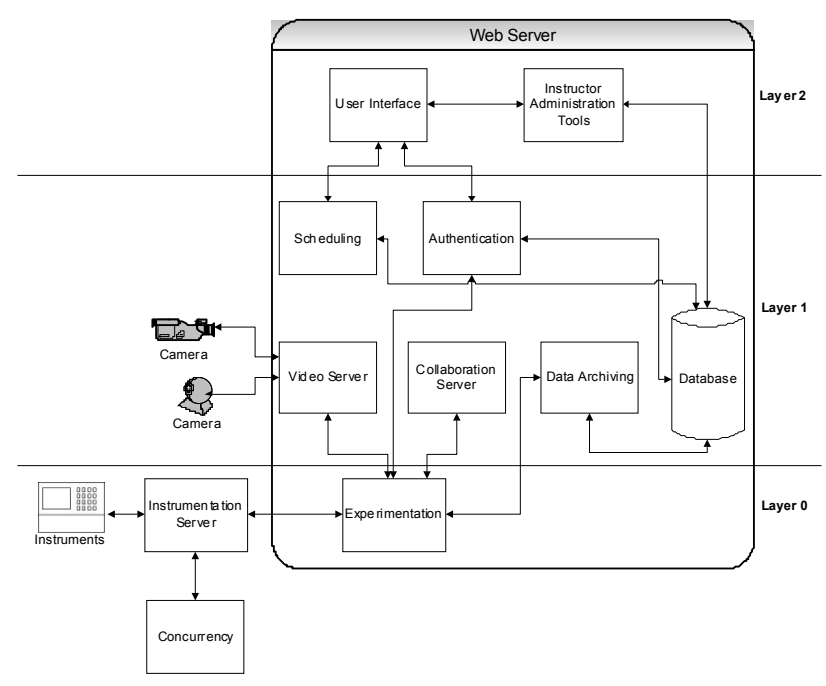

Figure 1. The new model

uling modules). Layer 2 includes the upper user interface and the instructor administration tools.

Each of the modules included in the model will be discussed in details in the following sections.

\section{DESCRIPTION OF SERVICES}

In this section, each of the modules that appear in the new model are analyzed. This analysis is based on a literature survey which mainly uses the RLEs described in [3$10]$.

\section{A. User Interface}

The user interface is a basic module available in any RLE model. It is the upper layer in our RLE model. This module is a web based application to interface the user with the available experimentation. From this application, a user should be able to do the following:

- Enter her/his login name and password

- Modify her/his password

- Add, modify, or check her/his scheduled times

- Download the data saved in earlier experiments

- Start and conduct an experiment.

- Collaborate with other users and/or with the instructor.

- Read general information from the instructor, information on experiments, grades, and others

- Send lab reports to instructor

\section{B. Instructor Administration Tools}

The instructor administration tools are web pages sometimes available in RLE models to assist the instructor in remotely configuring the laboratory experiment. It is in the upper layer of our RLE model and is considered as the instructor interface. From these web pages, the instructor is able to do the following:

- Post general information for the laboratory course

- Add, modify, delete, make available or make unavailable lab experiments with specific information for each experiment using a database for experiments.

- Put general announcements during the lab course
- Add / modify / delete users and/or groups, and assign users to groups using a users database.

- Assign available experiment schedule slots, and assign groups to these schedule slots

- Post lab report grades

- Perform experiments statistics based on groups archived data for experiments

- Start and conduct an experiment

C. Authentication

Authentication of users enable only registered students to access the lab experiments:

- Students entitled to run the experiments are entered in the system database along with username and password for each student. A student can change her/his password

- User Name and Password should be entered prior to starting any experiment

- Next, schedule is checked for the student (group) before granting access to the experiment.

- A short time before student's time ends up, the student (group) is notified to save the work. When the time is up, student (group) loses access to experiment.

- The instructor can disable a student account

\section{Scheduling}

In order to be able to access the lab experiments without conflict and congestion, scheduling of the experiments should be implemented.

- Each experiment (or lab server) should have an independent schedule for users access. In this schedule, each day is divided into time slots where experiments can be done. Some slots may not available because of maintenance or other reasons. The length of a time slot depends on the experiment.

- Schedules are entered by the instructor per students group on fixed slots. The instructor may set a strategy in allocating slots.

- The schedules are entered in the system database, and they are checked when a user logs into the system.

\section{E. Video Server}

To add real feeling of an experiment, it has to be viewed by a video camera. The following options are needed for proper video streaming:

- One or more video cameras are used to view the experiment. A camera can be movable or static. A user can select which camera to view, and set the number of frames per second.

- A video/audio server can be used to control and display outputs from the cameras. This may require some programming for the control of different cameras (using Visual C++ or Java Applets for example). A web page can also be designed with to display the camera output.

\section{F. Collaboration Server}

Collaboration is an important aspect in remote laboratory experimentation since it helps students within a group to collaborate even though they are not next to each other. 
Students in a group should be able to collaborate with each other or with the instructor during experiment session. The communication can be student to student, All group together, student to instructor, group to instructor. There are several types of collaboration: Chat window, Video/audio window, Video alone, Audio alone, Send files, Whiteboard. ConferenceXP is a may be used for this collaboration.

\section{G. Data Archiving}

Student Groups should be able to save experiment output results in the system database under their group name. The data is saved in the chronological order of the experiment and may be retrieved at any time and put in a popular data format (Text, Word, Excel, ...) for analysis. Archiving may also include the experiment state before quitting the experiment.

\section{H. Database}

A database is essential in the new model in order to be able to store and retrieve the following information:

- Users Profiles: In addition to general information on a user, the profile includes the username, password

- Instructors

- List of experiments

- Groups of students and experiments that can be accessed.

- Schedule of experiments

- Archived Data.

- Login data

- Lab report grades

\section{Experimentation}

As LabView is becoming the standard to control experiments, LabVIEW Web Publishing software can be used for basic Web publishing of experiments, and LabVIEW runtime client connectivity software with an Internet browser can be used for client software.

From the hardware side, computer controlled lab equipments having any of the following technologies are used: PCI/PCIX, Serial / USB, GPIB. Also electronic switching "Matrices" are used for changing experiment parameters (resistors, capacitors, circuit diagrams, ...).

\section{J. Concurrency}

Concurrency is to allow multiple users to login to the same experiment simultaneously. The number of users allowed to access an experiment at the same time is determined by the Users/Groups scheduling. LabVIEW software has the flexibility for multiple connections to the same experiment. An experiment slot is defined as an independent set of experimental tasks. This set must not interfere with other tasks provided by the experiment. Only one user at a time can control an experiment slot. The others may watch the slot. If a student wants to get a slot control, a request for that is launched. A request acknowledgement is sent back to him when the slot is free.

\section{CONCLUSION}

In this work, and due to the lack of well specified requirements for RLE, some recent RLE implementations models were considered, and the services provided by these models were identified. An improved model was concluded, and the services provided by this model were analyzed. This analysis study has lead to some specific requirements of the services in order to reach a common standard model that could be used to implement future RLE.

\section{REFERENCES}

[1] I. Mougharbel, A. El Hajj, H. Artail, and C. Riman, "Remote Lab Experiments Models: A Comparative Study", International Journal of Engineering Education, Volume 22 Number 4, 2006.

[2] A. El Hajj, I. Mougharbel and C. Riman, "On the Design and Implementation of Remote Computer Controlled Laboratory Experiments," CIBITIC Conference, May 2004, Beirut, Lebanon.

[3] S. H. Chen, R. Chen, V. Ramakrishnan, S. Y. Hu, Y. Zhuang, C. C. Ko and B. M. Chen, "Development of remote laboratory experimentation through Internet," Proceedings of the 1999 IEEE Hong Kong Symposium on Robotics and Control, Hong Kong, pp. 756-760, July 1999.

[4] J. Hua and A. Ganz. "A New Model for Remote Laboratory Education Based on Next Generation Interactive Technologies - A Generic Laboratory Plug-in using MS ConferenceXP Learning Infrastructure", Proceeding of ASEE New England Regional Conference, 2003, Orono, ME.

[5] R. Bachnak and C. Steidley, "An interdisciplinary laboratory for computer science and engineering technology," Journal of Computing in Small Colleges, Vol. 17, No. 5, April 2002, pp. 186-192.

[6] J.A. Rodriguez, E. Garcia, J. Rejas and M.A. Duran, "Web-Based Distributed Systems For Collaborative Remote Experiments," International Conference on Accelerator and Large Experimental Physics Control Systems, 1999, Trieste, Italy, p. 483-485.

[7] A. O. Abdul Salam and T. Ozkul, "Java-Based Cyber Technique for On-Line Engineering Labs", PPPJ 2003, 16-18 June, 2003, p. 109-112.

[8] T.A. Fjeldly and M.S. Shur, "Electronics Laboratory Experiments Accessible Via Internet", Lab on the Web, Wiley-Interscience, 2003. doi: $10.1002 / 0471727709$

[9] J.A. Del Alamo, V. Chang, L. Brooks, C. McLean, J. Hardison, G. Mishuris, L. Hui, "MIT Microelectronics WebLab", Lab on the Web, Wiley-Interscience, 2003.

[10] T. Zimmer and co-authors, "Instrumentation on the Web", Lab on the Web, Wiley-Interscience, 2003.

\section{AUTHORS}

C. Riman is with Computer Engineering Department, Fahad Bin Sultan University, Tabuk, Kingdom of Saudi Arabia (e-mail: criman@fbsc.edu.sa).

A. EI Hajj is with Electrical and Computer Engineering Department, American University of Beirut, Beirut, Lebanon (email: elhajj@aub.edu.lb).

I. Mougharbel is with Electrical and Computer Engineering Department, Lebanese University, Beirut, Lebanon (email: imadmoug@ul.edu.lb).

This work was supported in part by C.E.D.R.E. Program.

Submitted, September $29^{\text {th }}, 2010$. Published as resubmitted by the authors January $22^{\text {nd }}, 2011$. 